\title{
Exploring Metacognitive Judgment of Chemistry Teacher Candidates on Chemical Reading Activity
}

\section{Benny Yodi Sawuwu}

Department of Chemistry Education, Graduate School, Yogyakarta State University, Indonesia,bennyyodi@yahoo.com

\section{Crys Fajar Partana}

Department of Chemistry Education, Graduate School, Yogyakarta State University, Indonesia as specific judgments called metacognitive judgments. A think-aloud protocol was carried out to fifteen chemistry teacher candidates to express their judgments on chemical reading activities for question posing. Two chemical articles were designed to stimulate these judgments that were deepened by twenty open-ended questions of metacognitive judgment exploratory. A phenomenological reduction method was used to analyze the reading pattern and the question responses. The findings indicated that the chemical reading characteristics, the nature of the readers, and the perception toward the task demand had contributed to both the difficulties (ease-of-learning) and the work of memories (judgment-of-learning) on chemical reading activities. Some initiation factors were identified constructing the feeling states on the reading activity including the terminating strategy patterns (feeling-of-knowing). Confirmations of the memories used during the reading activity were divulged from seeking the familiarity to decide the memories (sourcemonitoring judgment). Expressions about the judgments were also disclosed quantitatively and qualitatively (retrospective belief) as goal-oriented and processoriented reader types. Based on the finding, the metacognitive judgment in chemical reading activity could be improved by designing the metacognitive chemical articles that determine the task, the sequence of intra-disciplinary chemical topics, the title-rooted phrases or clauses, chemical representations, terminologies, and interactive statements.

Keywords: chemical reading, chemical reading activity, chemistry teacher candidates, metacognitive judgments, think-aloud 


\section{INTRODUCTION}

Investigation of a reading activity of an academic article, like chemical reading, indicated that some mental actions were made by one's own self cognitively and metacognitively as a concurrently simultaneous activity (Khezrlou, 2012; Korpershoek, et al., 2015). During this reading activity, one was seeking for the structure of knowledge on the text by a sophisticated epistemological belief (Norris \& Phillps, 2012). By this belief, one would show some metacognitive behaviors such as selecting a strategy for understanding, applying the preliminary knowledge to solve problems, and checking the progress consistently (Pulmones, 2010). To know the cognitive and metacognitive activity toward the chemistry reading activity, posing questions after the reading activity could become an indicator (Demirdogen \& Cakmakci, 2014).

This investigation could be easier when using a think-aloud protocol, that is a technique to verbalize one's thought (Jacobse \& Harskamp, 2012). The advantage of this technique is to give the sight of the process of memory and actual thinking when one is reading, understanding, strategizing, processing, and deciding (Overton, et al., 2013) for revealing metacognitive judgment (Ben-Eliyahu \& Bernacki, 2015). When one conducted a metacognitive activity like reading by think-aloud to question posing, there were some specific judgments considered to make sure the accuracy of the action executed called as the metacognitive judgment (Dunlosky \& Metcalfe, 2009). Through these judgments, applying metacognitive knowledge on metacognitive strategy could be controlled (Ford \& Yore, 2012). In spite of the importance of these judgments, a problem came from the difficulty to get a whole comprehension about them, where the previous studies were conducted partially (Callender, et al., 2016; Thomas, et al., 2016).

A qualitative analysis could get a whole description about that metacognitive phenomenon (Siegel, 2012). One of the qualitative approaches that could be used is a phenomenological study (Vierkant, 2017). Nevertheless, this approach had a shortcoming, longer time needed (Jacobse \& Harskamp, 2012). By analyzing in-depth the representative samples that had similar epistemological beliefs of students with the same metacognitive type, this shortcoming would be covered (Pulmones, 2010).

Chemistry teacher candidates, as the agents to assess the students' metacognitive, should have the capacity to read the chemical reading and to pose the chemical problem before they would judge their students on the future. Particularly chemistry education domain has certain characteristics that evolve during the world development in this 21 st century. This research was conducted to explore the metacognitive judgment of chemistry teacher candidates in the reading activity of a chemical article. This study aimed to reveal the metacognitive judgment when reading the chemical article and the components of the chemical article which had contributions to increase the metacognitive judgment in a chemical reading activity. The findings of this study were expected to help educators design their chemical articles for their students. 


\section{LITERATURE REVIEW}

\section{Chemical Reading}

There were four aspects that should be considered to design a chemical reading for transfer the chemical knowledge to readers. The first was the structure of chemical readings or articles of chemistry. It should determine the length of the article, type of article, task demand, and interdisciplinary level (Herscovitz, et al., 2012). A short article was considered up to four-hundred words. The type of the article should give integrated complex information. The task demanded should be in a specific chemical context and need various thinking skills and chemical aspects. For interdisciplinary level, the information could be the integration of two or more chemistry domain or other disciplines. The second is the basic chemistry multiple-representative. There are four representatives that should be considered in every chemical reading: phenomenology, model, symbol, and process aspects. The phenomenology aspect is phenomena representative as an experience got through the senses that consist of clear empirical properties of laboratory and daily life and could be measured. The model aspect is seeking for the qualitative explanation of the phenomena and modeling the submicroscale things. The symbolic aspect is seeking for the quantitative explanation of phenomena (Gilbert \& Treagust, 2009). The process aspect is how to understand the way of interactions of matters (Kaberman \& Dori, 2009).

The third is the humanistic approach in chemistry education that has three levels: techno-science, contextual, and critical level (Sjostrom \& Talanquer, 2014; Sjostrom, et al., 2016). Science in technology or its application promotes techno-science and technical-instrumental training, discusses the daily context, focuses on analysis about the real world or actual experiences, and helps construct the relationship between the phenomenology and model aspects (mesoscopic, multi-particle, and supra-molecule). The meaningfulness of science in everything emphasizes the social aspect (sociochemistry) and scientific citizenship. The critical level is facing the science for transformation. It is an understanding of the complexity of the life, the society and the interaction of each other, and the responsibility and collective action toward the balancing of ecosystem and society (socio-eco-justice) and global sustainability.

The fourth is about the reading characteristic that should be iterative, interactive and principled (Norris \& Phillips, 2012). Iterative means that specific skills were needed to understand the content and purpose of the chemical reading. Interactive means that served information allows mental activities as responses to the reading. The principal character in chemical reading requires constructing the complete and consistent information. Complete means the elements of info given in unity data excluded the wideness and depth of explanation. Consistent means that the information discussed defers to a clear concept or topic.

\section{Metacognitive Judgment}

Metacognitive monitoring is an appreciation process or progress evaluation that proceeds on a specific cognitive activity that becomes basic set for what the thing will 
be understood (Dunlosky \& Metcalfe, 2009). This monitoring is a metacognitive judgment (de Bruin, et al., 2017) and decision making (Callender, et al., 2016). Through this metacognitive judgment, the implementation of metacognitive knowledge via metacognitive strategy can be controlled (Ford \& Yore, 2012). Therefore, the metacognitive judgment can be explained as evaluation and reflection of metacognitive strategy that is used based on metacognitive knowledge on one's cognitive activity processes. On the metacognitive activities, one would conduct some considerations to decide by his/her own self and to calibrate his/her abilities measured as judgment accuracy (Mathabathe \& Potgieter, 2014; de Bruin, et al., 2017). There are two judgment accuracies. They are relative accuracies or resolution and absolute accuracies or calibration. Calibration refers to the difference between actual performance and perceived performance (Dunlosky \& Metcalfe, 2009; Mathabathe \& Potgieter, 2014). The resolution shows one's metacognitive predictions of one thing to something that is expressed commonly by a correlation coefficient (Dunlosky \& Metcalfe, 2009). These accuracies judgment could be classified to overconfidence/overestimate, confidencerealistic, and underestimate (Mathbathe \& Potgieter, 2014; de Bruin, et al., 2017).

Aspects of metacognitive judgments are ease-of-learning judgments, judgment of learning, feeling-of-knowing judgment, source-monitoring judgment, and confidence in retrieved answer or retrospective belief (Dunlosky \& Metcalfe, 2009; Nelson \& Narrens, 1990; Dunlosky \& Bjork, 2008). These basic components of metacognitive judgments occurred on acquisition and retrieval steps (Nelson \& Narrens, 1990). For the ease-of-learning judgment (EOL) was defined as a judgment about how easy or difficult one learned the known things (Dunlosky \& Metcalfe, 2009), on the planning step especially on the advance of acquisition that became the predictor of learning velocity while one allocated the time during the consideration understanding the things instructed (Nelson \& Narrens, 1998). This metacognitive judgment related to the simplicity or complexity of knowledge based on quantity, clearness of information, completeness, and authority of evidence or validity (Mason, et al., 2010).

The judgment-of-learning (JOL) was a judgment about the possibility to memorize the recently instructed things on the next test that was divided by immediate (instantaneously made after learning something) and delayed (seriously made after learning in relative time) (Dunlosky \& Metcalfe, 2009). This judgment was one's prediction and awareness about unknown things (Veenman, 2012; Chiu \& Linn, 2012). It occurred on monitoring steps (Dunlosky \& Bjork, 2008), particularly on during or after acquisition phase as the predictor to the next performance. This judgment consisted of the unevaluated information, the truth related to the expertise, the truth related to the comparison to other sources, and the truth related to the scientific evidence (Mason, et al., 2010). If this judgment is too high that one feels having knowledge of it, so one will decide to learn not, and if one decides to learn, so his/her beliefs will change that it has been more difficult (Metcalfe \& Kornell, 2005). It happened because the consideration of time allocation was affected by choice and perseverance (Metcalfe, 2009).

The feeling-of-knowing judgment (FOK) is a judgment about the possibility to recognize the unrecalled answer on the next test (Dunlosky \& Metcalfe, 2009). This 
judgment related to one's prediction about non-mastered things (Veenman, 2012), the things that had been known before or in another side to compare the familiarity of something faced to another before, this case is called feeling-of-familiarity (FOF) (Chiu \& Linn, 2012). This judgment occurred on monitoring steps (Whitbread \& Cardenas, 2012), especially on during or after retention phase or even on quick initiation or termination of retrieval phase related to judgments about known/remembered things when conducting a test. The feelings did not only relate to the thought monitoring but also relate to the thought control, so this feeling was also called epiphenomenon with the consciousness (Efklides, 1999). Based on that concept, some concepts arose on metacognitive judgment called metacognitive feelings (Norman, et al., 2010), including feeling-of-difficulty, tip-of-the-tongue, and blank-in-the-mind (Efklides \& Misailidi, 2010). The feeling-of-difficulty (FOD) was the manifestation of monitoring and controlling functions of metacognitive knowledge refer to the sources of task difficulties (Efklides, et al., 1999). The tip-of-the-tongue (TOT) related to the curiosity judgment that was high but not balances on the skills to recall the knowledge signed by cue toward ideas or to remember the things related to the ideas (Dunlosky \& Metcalfe, 2009). The blank-in-the-mind (BIM) was the temporal experience that occurred when there was not any content on the consciousness caused by the failure of upcoming-memory maintained to be memory (Efklides \& Touroutoglou, 2010).

The source-monitoring judgment (SM) was defined as the judgment made during a test criterion related to the origin of certain memories (Dunlosky \& Metcalfe, 2009), and to one's own understanding to decide the knowledge gap (Chiu \& Linn, 2012). This judgment included the guessing strategy metacognitively (Batchelder \& Batchelder, 2008). It was influenced by the clearness, perfection, agreement or disagreement with own knowledge and the use of the knowledge for the learning (Mason, et al., 2010).

The retrospective belief (RB) was the judgment about the possibility that a response to a test was correct (Dunlosky \& Metcalfe, 2009), that can be expressed in percentage and/or verbal statements (Kleitman \& Moscrop. 2010). This judgment occurred after recall conducted related to the response of what the tests have done (Nelson \& Narrens, 1990). This case indicated that perceived performance affected by finale response to the learning process. This belief of knowledge includes the information that was stable for the time period, the information that was stable occasionally, and the information that was changeable during the time (Mason, et al., 2010).

\section{Deficiencies in Metacognitive Judgment Research}

The studies $t$ conducted about this metacognitive judgment have least three deficiencies. The first deficiency in these studies was about the partiality of the investigated domain in metacognitive judgment. For examples, the studies were only about the JOL (Finn \& Metcalfe, 2014; List \& Alexander, 2015), the FOK (Schwartz, et al., 2016), the SM (Rummer, et al., 2016), or the RB (Mathabathe \& Potgieter, 2014; Callender, et al., 2016). This became a problem since the discussion about the single aspect could not be separated with other aspects. When a study discussed JOL as a prediction of the unknown thing, it should be discussed concurrently with the FOK and SM in order to get the whole understanding of the memorization process. The usual combination used 
in the studies was only with the RB in categorizing the confidence level (Thomas, et al., 2016). The second deficiency was about the limitation of the quantitative analysis especially in determining the calibration (Bol \& Hacker, 2012), resolution (Schwartz, et al., 2016), or both of them (Finn \& Metcalfe, 2014). These studies that emphasize the quantitative analysis were oriented to the result of the metacognitive activity. In fact, the metacognitive in the result-oriented study (the result of thinking) is not enough because almost all of the metacognitive aspects occur in the mind or on the process of thinking (Dunlosky \& Metcalfe, 2009; Norris \& Phillps, 2012; Schraw, et al., 2012). So, the quantitative aspect was not appropriate to describe the process in each aspect of the metacognitive judgment. Even in the qualitative analysis, the discussion did not explore the process in the process of making a judgment (Tuysuzoglu \& Greene, 2015). This resulted in the third deficiency that the explanation did not focus on the process.

\section{Research Question}

Covering the deficiencies listed before, this study used the qualitative method embedded with a think-aloud protocol to explore the process of making a judgment in chemical reading activities and to find the component of the chemical article that contributes to the metacognitive judgment attainment. The research questions of this study are:

1. How are the metacognitive judgments when reading a chemical article which is designed by stimulating the readers' metacognitive strategy in:

a. Judging the difficulty of the chemical article (EOL aspect).

b. Memorizing the information of the chemical article (JOL aspect).

c. Controlling the memorization of the chemical information (FOK aspect).

d. Monitoring the memorization of the chemical information (SM aspect).

e. Making sure the belief of the chemical reading comprehension (RB aspect).

2. How should the chemical article be designed to increase the readers' metacognitive judgments in a chemical reading activity?

\section{METHOD}

\section{Context and Participants}

This was a qualitative study of 15 chemistry pre-service teachers in third years of a public state university in Yogyakarta, Indonesia. All of them were female and from 19 to 21 years old. They were in the international program that used a bilingual class in Indonesia Language and English during their courses. They participated voluntarily in this research outside the regular class activities. An ethical consideration used to protect the data of participants that was stamped in an agreement between each participant and the researchers (Taber, 2014; Sadowski \& McIntosh, 2015).

\section{Material}

Two chemical readings have been designed for stimulating metacognitive strategy in reading activity. The first reading was an article about the application of chemical equilibrium in human teeth. The second reading was about chemical equilibrium in esterification. The articles were overlapping with other chemistry domains and other disciplines, that fulfilled some criteria about chemical reading as mentioned before, to 
stimulating the participants to pose problems in question-form at the metacognitive level. The articles had been validated by experts in related disciplines, and some suggestions form the experts had been used to consummate the reading. Moreover, there were 20 questions of metacognitive judgment exploratory arranged to reveal another metacognitive aspect that was not observed during the reading and posing question activities. The questions were open-ended questions (the questions were derived from each component of EOL, JOL, FOK, SM, and RB as discussed before). They had been validated by two experts on chemistry education and psychological education. Some suggestion from experts had been used to complete the questions' visibility

\section{Procedure}

Participants should pose two problems in question-form after they read the article as the result of thinking and reflection of the article. After they made the questions, they should answer the open-ended questionnaire by themselves. The time was limited to 45 minutes to finish their activities. A think-aloud protocol was used in this reading procedure for collecting data about metacognitive activities during reading the article (Jacobse \& Harskamp, 2012). The first, each participant was given the reading and had been simulated about the procedure of think-aloud for recording. Each participant had been requested to vocalize or verbalize their thoughts in front of the recorder during they were reading. For validating the think-aloud technique the reading activity was conducted one-by-one (not in a group), without researchers interruption, at the comfort place that participant selected before, and in their spare time (Overton, et al., 2013). Before each participant began to read, they were asked about some terminology of chemical equilibrium that had become the problems on the understanding of the chemical equilibrium and the topic of the articles (these terms were selected because they tended to undergo some systematic and random error (Kousathana \& Tsaparlis, 2002).

\section{Data Analysis}

Data recorded about the reading activity, question posing activity, and self-interview were transcripted by participants' approval. Audio and paper-based documents were encoded by special codes to enclose participants' data. Transcriptions of data were checked by participants and independent reviewers to inspect time accuracy of each passage segment and the word precision of think-aloud activity. Coding data of analysis were verified through a focus group discussion with the experts related. The transcriptions were arranged sequentially between the textual words and think-aloud word. Every segment (sentences, equations, and figures/graphs) was measured to the reading rate. This measurement was just only for categorizing the data in the detailed segment of reading patterns.

Next, seeking for the difference or delta $(\Delta)$ between the reading rate of think-aloud and textual word (relative to the time spent on each participant) was conducted to analyze the reading pattern (Mathabathe \& Potgieter, 2014) and to find "what" the metacognitive activities during the reading process. The delta gave a description of the reading pattern. The positive value of the delta showed that participants were more in 
think-aloud. The zero value of the delta showed that participants were equal on thinkaloud and normally textual word. The negative delta indicated that participants were less on think-aloud, did not read the words, and stayed in silence for several seconds.

A phenomenological reduction method was used to analyze the reading phenomena (Sadowski \& McIntosh, 2015; Chopra, et al., 2017). All data transcripted then were reduced (horizonalization of data). It was carried out by deleting the statements of thinkaloud expressions that were not relating to the activities on each parallel segment of reading the article, posing the questions and answering the questionnaire. After this reduction, the data would be coding and categorized in the same theme that represented the specific expression and the findings of the metacognitive strategy in the reading activity of the chemical article. The coding from the reading pattern was used to find neomatic themes (what the phenomenon is) and the coding from the think-aloud activity and self-interview was used to find neosis themes (how the phenomenon is) (Yuksel \& Yildirim (2015). Then, data verification was conducted to clarify and reinforce the themes. The neomatic themes were unified as formulation the textural definition but the neosis themes were as the structural definition. By blending the textural and structural definitions and adding with data interpretation, the themes were merged to be the essential definition of metacognitive judgments in chemistry reading activity.

\section{FINDINGS AND DISCUSSION}

\section{How difficult the text I read?}

As the chemical reading contained some specific characteristics, the perception of the readers also followed to judge about their convenience when conducting a chemical reading activity (Pulmones, 2010). In this EOL judgment during the reading activity, five impetus factors were investigated for difficulties in chemical reading activity. They were about terminology in the article, type of the article, information in the article, readers' characteristics, and task demand. First, terminology had become the more reasonable factor for chemical reading comprehension than others. Based on the thinkaloud toward both articles, some terms were detected as the fuzziness for some readers. The readers confessed that there was no information explained in the text about the terms. This case affected the comprehension of one sentence about the term. They said that they had no idea about those terms. Even not only chemical terms but also other discipline terms were given to the article. The spots of unknown familiar words as mentioned above indicate a less-think-aloud activity (the delta closed and converged to 0 ). The fuzziness toward the unfamiliar, unknown, and unexplained terms on the chemical reading texts, stimulate the readers just thought on curiosity to find definition about them (Demirdogen \& Cakmakci, 2014). This inquisitiveness was exposed to some questions posed that interrogated about the definition of some unknown terms.

The second was from the type of the article. If to comprehend the article needed some iteration, from readers' point of view, the readers would undergo a transition on their mental activity. When they did not understand on the first time of reading the text, they would face two options; either passed the text or iterated reading the text. Deciding to iterate the text made the perception about the text was more difficult than the text before 
(Metcalfe \& Kornell, 2005). Moreover, the curious information would attract the attention of the readers to stay on reading. The curious expressions were denoted by the positive value of delta on the reading pattern. The spots showed that the contextual information tended successfully fetching the inquisitive expressions when the chemical reading activity.

The third was also from the information on the text about the clearness and validity of the text. The clearer and the more valid the information, the more difficult the readers found the problem in the text. This effect was affected by the fourth factor, the readers themselves. The readers did not accustom to inquire something during their reading performance, especially in chemistry. They tend to be a text-based reader who believed absolutely what the text they read without any thought consideration (Norris \& Philips, 2012). This case was aggravated increasingly by their dislike toward the chemical topic discussed in the text, particularly the chemical equilibrium topic that was admitted as the aversion on the readers' confessions (Kousathana \& Tsaparlis, 2002).

The last impetus factor was task demand. The readers' perceptions of the task acted affecting the strategy they used during the reading performance (Metcalfe \& Kornell, 2005). The required time was used as a consideration to judge to accelerate, decelerate, pass, or iterate the text. The perception toward the goal also elicits the problem for the readers (Veenman, 2012). In this case, the goal was to pose two question on each article focusing on the chemical equilibrium and its application. The participants' disliking of the chemical equilibrium boosted their perception of the difficulties to pose the question.

\section{How my memory of the text I read?}

Some elements for memorizing on the chemical reading activity were identified similar to the sources from the EOL factors. On this JOL, the prediction and the awareness about the unknown thing that should be learned were constructed by the readers, the structure of the article, the content of the article and the task required. The readers who were judging themselves to go forward reading, back reverse for iteration, or pass the sentence to the next sentence were affected by their focus on the reading activity. This focus related to the awareness of their own self (Veenman, 2012; Chiu \& Linn, 2012). When the readers judge themselves that they had no capacity to understanding the topic, they could not design a problem, and they had no interest to the topic, then they would judge to minimize their effort (Metcalfe \& Kornell, 2005). Moreover, the nature of the readers themselves that tended to attract to the preferred information, when they could not find the preferred information on the text, they would accelerate their reading speed or pass the text to the next interesting parts of the text.

The terms that were given in the text (escaped from familiar or unfamiliar, known or unknown, new or strange) would be more memorized in the readers' mind. Although all participants were chemistry teacher candidates who had interest in chemical education, the chemical equation was not the memorized thing for all of them. The chemical equation spots had decelerated reading speed and closed to zero even the negative delta. Some readers just formally vocalized the equation without analysis about the reaction. Even some readers stayed in silent looking for the equation and the others passed the 
equation to another interesting part of the text. The chemical representation had been indicated as the memorizing signals in this chemical reading activity. On the chemical representation spots, the delta diffuse on the spots both independent and dependent chemical representations. This pattern indicated similarly to the chemical equation pattern that some readers used the representations to be signals for memorizing the information about the text's idea.

The content of the text also contributed to the memorization of the chemical reading. For the text-based readers, they noticed that the familiar chemical information had been memorized in their mind (Norris \& Phillips, 2012). They focused on the title-based text. For the first article entitled "Demineralization and Remineralization", every phrase or clause containing "demineralization" and "remineralization" had been signaled by the important part to memorize. Like the first article, the second article entitled "Esterification" had been indicated that every esterification phrase or clause was denoted as the memorizing spots. For the belief-background-based readers, in this case, their background belief was related to chemistry, their perspective about the related chemical concepts also used as the memorizing spot determination (Norris \& Phillips, 2012). On this spots, some errors in chemical equilibrium understanding were detected such as the similar concept between reaction rate and chemical equilibrium, the use of a catalyst, etc. In addition, the secondary data of the text such as the detail information or explanation about a process became the signals for memorization. The critical-based readers underwent critical metacognitive think-aloud on the contextual text, notice statement and contrary statement mentioned in the text.

The last, this JOL was also promoted by the task demand. The task comprehension to find the problem in the text was considered to the performance of the chemical reading activity. For posing questions related to the chemical equilibrium and its application on the text, the readers had designed their own model about the question they would pose. For the contextual-based readers, they tended to focus on every contextual information to link to their experiences. For the text-based, they were seeking for the definition or understanding about the unexplained information (Norris \& Phillips, 2012). And for the critical-based readers, they posed the interrelationship among the problems they found in the text. Strategy for utilizing time was also determined to accelerate or decelerate their quest for the goal (Metcalfe, 2009). Thus, the JOL on the metacognitive chemical reading activity (involving think-aloud and question posing) required the cohesiveness contribution from each impetus.

\section{How do I control my memory when reading?}

On this chemical reading activity, some containment of FOK aspects in each state were identified. For the FOF state, the judgments were initiated by the characteristics of the text given such as representation figures, curious-trigger statements, chemical reactions, and the unfamiliar terms but contextual for the readers. The TOT state was also affected by those text's characteristics added by the recording effect and the difficulty on diction when verbalizing and arranging the questions. When the readers know they should record themselves, some anxiety elicited in their mind. Besides on the nature of the readers themselves, the anxiety appeared as the think-aloud validity and the nature of the 
readers that accustomed to voiceless learning activities. The anxiety also caused the FOD when the readers try to understand the chemical text. The feeling was a response toward anxiousness of the failure to reach the goal, to understand the text, to have nothing time left, and to have the unable skill required. This FOD tended to fail the readers for understanding the chemical reading that could impact the quality of the questions posed. If the readers pushed themselves on these difficulties to stay on the reading performance, they would read the text as just reading physically but not mentally (Metcalfe \& Kornell, 2005). They read the text without infiltrating the text or try to get a comprehension of the text. This condition could initiate the BIM state. In contrary, if the readers thought too much about the text for an understanding, they would topple themselves on this state (Efklides \& Touroutoglou, 2010). This condition also occurred when the readers faced the dilemma between "what I am puzzled" and "what I am contemplated". Some participants confessed that their negative mood also garbled their thought and bothered to their concentration toward the reading activity.

Some strategies for terminating the states conducted were by the participants during this reading activity. To terminate the FOF state, the readers would link the chemical representations and terms to the text of related sentences and experiences. Some chemical readers selected to stay in silent for a moment for refreshing their mind to handle TOT, FOD, and BIM states. Some readers tried to re-read the text for terminating the TOT and FOD states. The others tried to motivate themselves and do another activity when they were in FOD and BIM states. Another was rethinking, expecting a help, and trying to say something until finding the words.

\section{How do I know my memory work well?}

Recognizing the information they found from the text till deciding the information for designing the questions was monitored by a source-monitoring judgment that made rapidly during the reading comprehension. Four steps were identified in this research that the readers undertook and underwent during the chemical reading performance for confirming what the memory of the information should be elected. The first, after the readers found the terms, phrases, clauses, sentences, or figures, they would be seeking for the familiarity about them by recalling and recollecting their memories related them. There were three sources of the memory should be considered, from kinesthetic (memory about the experience), visual and audio memories. This recollection was a highly similar indicator of a single memory retrieval process (Martin, et al., 2011) which contributing to their recognition decisions (Ingram, et al., 2012).

Secondly, they were seeking for the detail of memory to measure the accuracy of the result from recollection and familiarity before. In this step, the readers weighed the sum of memories, the sources of the memory, and the related memory. For notions of memory accuracy, all memories could be the true memory or false memory in generating personal meanings (Conway \& Loveday, 2015). False memories were affected by sleep deprivation on susceptibility, which could have dire consequences (Frenda, et al., 2014), or not only of the general familiarity but also the result of conscious recollection. For justification toward this detailed memory, then the third, the readers were seeking for more information related to the information they had. In this step, the readers were 
seeking for the close memory related the information, seeking for when, where, how, and why the memory occurred, and rethinking to investigate chronologically. If the readers worked hard to memorize, they would become more difficult in remembering and the memory would associate the familiarity of phenomenological experiences to elicit the false remembering (Anderson, et al., 1994). The last, to decide the memory the readers alerted themselves about the completeness of their remembering. They judged about the certainty of the memory: "I am sure about the memory" (refer to the iterative thinking process always bring in similar comprehended belief) or "I am not sure about the memory" (refer to the iterative thinking process bring in the clogged comprehension). Then, they judged about the confirmation of the memory: "I know" (implied that the detailed memory about the information had been confirmed) or "I do not know" (implied that there is no confirmation about the memory related to the information). Finally, they would judge to the relevance of the memory to the task: "My memory is relevant" (means that the memory is important used to question posing) or "My memory is not relevant" (means that the memory is unrelated to the task).

\section{How my belief in my reading comprehension?}

Through this study, the readers showed the level of confidence in the retrieved answer (goal-oriented) and in renewed understanding (process-oriented) by percentage and/or verbal statements (Kleitman \& Moscrop. 2010). In this case, the goal-oriented was the chemical question posing and the process-oriented was the chemical reading comprehension. When the confidence more than $80 \%$, it implied that "I am sure with my result" and "I am optimistic to my last understanding". The $80 \%$ confidence refers to "I think my result is good" or "I think my understanding is sufficient". The $60 \%$ confidence means that "my result is adequate" or "I think I need more time to modify my understanding". The $40 \%$ implies that "I think my result is sufficient" or "I am stuck on my little understanding". The confidence up to $20 \%$ means that "I am not sure with my result" or "I have not found my understanding". And the $0 \%$ confidence level was "I don't know to judge myself" and "I am pessimistic to judge what I have done". These confidences depended on the judgments made from four previous aspects (Finn \& Metcalfe, 2014; List \& Alexander, 2015; Schwartz, et al., 2016; Rummer, et al., 2016)

Based on those two orientations, the retrospective belief of the readers on these chemical reading activities divided the readers into four types. The first readers were the adroit-reader type. The readers had a high confidence in their result and understanding about the reading performance. The second was the dubious-reader type. The readers tried to have a high confidence in their result yet actually they had a problem to make sure their understanding. The third was the mind-restrained-reader type. The readers had a confidence in their understanding of the chemical reading. They could link and organize their understanding yet they had a discomfort to express their understanding or ideas to the goal required. The last was the indecisive-reader type. The readers had some problems such as under-confidence, pessimistic, and uninterested. 


\section{Designing the Chemical Article for Improving the Metacognitive Judgment}

According to the findings of each aspect of the metacognitive judgment in chemical reading activities, the metacognitive chemical article should be designed by determining several components as mentioned below.

1. It should have a metacognitive instruction to begin a chemical reading activity for example to have a question posing, concept mapping, etc. The specific tasks are required such as time-limited, the specific chemical topic, and the specific technique (e.g. think-aloud, group discussion, etc.).

2. The topic should be proper to the sequence of the chemical topics. This includes the intra-disciplinary of main chemical concepts used in the chemical article (Herscovitz, et al., 2012). The additional information or advanced chemical concepts used in the article should be explained in order to avoid the students' confusion.

3. The topic and the title of the article should be interesting and contextual. Every important information should use the title-rooted phrases or clauses to help students find the important memorization spots in the chemical article.

4. Dependent multiple chemical representations should be in every chemical article (Gilbert \& Treagust, 2009). The phenomenology representation in the beginning and the end of the article can attract the interest of students. The chemical equation and symbol or model representation should be combined with phenomenological representation and others to make contextual and meaningful chemical information.

5. Make sure that all definitions and explanations about unfamiliar terms should be explained in the chemical article explicitly or implicitly. Try to present the application of the chemical concept first, then explained the concepts without showing the complexity. The complexity of the article can be added gradually when the students have been familiar with the topic and the chemical reading activity.

6. The chemical article should be interactive to the students (Norris \& Phillips, 2012) through confirmation, notice, and contrary statements, analogies or metaphors, a guided statement to think or ask something, reflective and persuasive statement, etc.

7. Make sure that the teachers, who command the students to read, have to read and understand the article first. Teachers should check that the components mentioned before must have been in the chemical article and should measure the article proper to students based on the language, the clearness, the completeness, and the precision of the chemical concepts.

\section{CONCLUSION AND SUGGESTION}

Exploration of the metacognitive judgment on the metacognitive chemical reading activity indicated that the judgments decided during the reading comprehension (process) affected reciprocally the judgments for the question posing (result). When the readers measured themselves toward the chemical reading they faced, some difficulties were found contributing to their reading performance such as accelerating or decelerating their reading speed, vocalizing or muting on think-aloud, and passing or continuing reading the text. Terminology in the text, type of the article, information characteristics, the readers' characters, and the task demand have been the impetus factors for the difficulties. Every segment of the chemical article should have certain 
elements for signaling the memorization spot. For chemical information, the spots were labeled by chemical terms, chemical equation and chemical representations, either dependently or independently. The readers' perception of the topics and their awareness about themselves also affected the task comprehension and strategy for seeking the memorization spots. The text-based readers focused on the title terms of each sentence in the text. The belief-background-based readers denoted the chemical information related as the spots for expanding their memory and understanding. The critical-based reader chased the contextual parts of the article for their preparation to reach the goal.

Facing the difficulty and seeking for the memorization spots were controlled by some metacognitive feelings. The FOF accompany in every memorization process so that the impetus factors also influenced this feeling. When the thinking process and think-aloud activity were inequality, the TOT state had the higher possibility. If the anxiety was not controlled during the reading performance, the FOD would appear and would prolong to the BIM state. Some strategies had been identified as the termination ways toward each feeling state. The silent activity during the reading performance could be indicated for the strategy to terminate the feeling or shift to other segments of the text. Thus, the readers knew that their memory and understanding about the chemical reading worked well by way of some steps in remembering process from the familiarity and recollection the memory to decide the confirmation about the memory. The beliefs toward the confirmation were expressed retrospectively as confidential degree toward the goaloriented and process-oriented quantitatively or qualitatively.

The chemical reading should be designed stimulating the metacognitive activity of the readers. The definition of the terms used should be considered to elicit the curiosity and critics toward the text. The contextual topic on chemical readings should be as the trigger for more positively metacognitive judgments. The chemical representations required for the memorization spots dependently. The question posing activity after the reading performance, seeking for the important information on the text, and summarizing the text (on brainstorming or concept mapping) could be the effective alternatives for confirmation of the reading comprehension. To train the students to be the adroit-readers, the teachers could conduct this think-aloud activity. This activity gives advantages for the teachers to analyze their students' errors on the chemical conceptions, to determine the further judgments about the next class, and to evaluate and develop the sufficient chemical reading for their students. As the chemistry teacher candidates, the readers especially should have accustomed to critical-based reading and become the adroit-readers for preparing themselves to be the metacognitive assessors. Therefore, the assessment of the thinking process during chemistry classes could be conducted effectively and the students' or the readers' need for chemical reading comprehension could be handled by the proper treatments.

\section{ACKNOWLEDGMENTS}

The authors are very grateful to Indonesia Endowment Fund for Education (LPDP) for supporting this research. 


\section{REFERENCES}

Anderson, M. C.; Bjork, R. A. \& Bjork, E. L. (1994). Remembering can cause forgetting: Retrieval dynamics in long-term memory. Journal of Experimental Psychology: Learning, Memory, and Cognition, 20/5, 1063-1087.

Batchelder, W. H. \& Batchelder, E. (2008). Handbook of Metamemory and Memory. New York, NY: Psychology Press.

Ben-Eliyahu, A. \& Bernacki, M. L. (2015). Addressing complexities in self-regulated learning: a focus on contextual factors, contingencies, and dynamic relations. Metacognition and Learning, 10, 1-13.

Bol, L., \& Hacker, D. J. (2012). Calibration research: where do we go from here? Frontiers in Psychology, 3, 229.

Callender, A. A.; Franco-Watkins, A. M. \& Roberts, A. S. (2016). Improving metacognition in the classroom through instruction, training, and feedback. Metacognition and Learning, 11/2, 215-235.

Chiu, J. L. \& Linn, M. C. (2012). Metacognitive in Science Education: Trends in Current Research. Dordrecht: Springer.

Chopra, I.; O’Connor, J.; Pancho, R.; Chrzanowski, M., \& Sandi-Urena, S. (2017). Reform in a general chemistry laboratory: how do students experience change in the instructional approach? Chemistry Education Research and Practice, 18, 113-126.

Conway, M. A. \& Loveday, C. (2015). Remembering, imagining, false memories and personal meanings. Consciousness and Cognition, 33, 574-581.

De Bruin, A. B. H.; Kok, E. M.; Lobbestael, J. \& de Grip, A. (2017). The impact of an online tool for monitoring and regulating learning at university: Overconfidence, learning strategy, and personality. Metacognition and Learning, 12/1, 21-43.

Demirdogen, B. \& Cakmakci, G. (2014). Investigating students' interest in chemistry through self-generated questions. Chemistry Education Research and Practice, 15, 192-206.

Dunlosky, J. \& Bjork, R. A. (2008). Handbook of Metamemory and Memory. New York, NY: Psychology Press.

Dunlosky, J. \& Metcalfe, J. (2009). Metacognition. Los Angeles, LA: Sage.

Efklides, A. \& Misailidi, P. (2010). Trends and Prospects in Metacognition Research. New York, NY: Springer.

Efklides, A. \& Touroutoglou, A. (2010). Trends and Prospects in Metacognition Research. New York, NY: Springer. 
Efklides, A.; Samara, A. \& Petropoulou, M. (1999). Feeling of difficulty: An aspect of monitoring that influences control. European Journal of Psychology of Education, 14/4, 461-476.

Finn, B., \& Metcalfe, J. (2014). Overconfidence in children's multi-trial judgments of learning. Learning and Instruction, 32, 1-9.

Ford, C. L. \& Yore, L. D. (2012). Metacognitive in Science Education: Trends in Current Research. Dordrecht: Springer.

Frenda, S. J.; Patihis, L.; Loftus, E. F.; Lewis, H. C. \& Fenn, K. M. (2014). Sleep deprivation and false memories. Psychological Science, 25/9, 1674-1681.

Gilbert, J. K. \& Treagust, D. F. (2009). Multiple Representations in Chemical Education, Dordrecht: Springer.

Herscovitz, O.; Kaberman, Z.; Saar, L. \& Dori, Y. J. (2012). Metacognitive in Science Education: Trends in Current Research. Dordrecht: Springer.

Ingram, K. M.; Mickes, L. \& Wixted, J. T. (2012). Recollection can be weak and familiarity can be strong. Journal Experimental Psychology: Learning, Memory and Cognition, 38/2, 325-339.

Jacobse, A. E. \& Harskamp, E. G. (2012). Towards efficient measurement of metacognition in mathematical problem solving. Metacognition and Learning, 7/2, 133-149.

Kaberman, Z. \& Dori, Y. J. (2009). Metacognition in chemical education: Question posing in the case-based computerized learning environment. Instructional Science, 37/5, 403-436.

Khezrlou, S. (2012). The relationship between cognitive and metacognitive strategies, age, and level of education. Reading Matrix, 12/1, 50-61.

Kleitman, S. \& Moscrop, T. (2010). Trends and Prospects in Metacognition Research. New York, NY: Springer.

Korpershoek, H.; Kuyper, H. \& van Der Werf, G. (2015). The relation between students' math and reading ability and their mathematics, physics, and chemistry examination grades in secondary education. International Journal of Science and Mathematics Education, 13/5, 1013-1037.

Kousathana, M. \& Tsaparlis, G. (2002). Students' error in solving numerical chemicalequilibrium problems, Chemistry Education Research and Practice in Europe, 3/1, 517.

List, A., \& Alexander, P. A. (2015). Examining response confidence in multiple text tasks. Metacognition Learning, 10/3, 407-436. 
Martin, C. D.; Baudouin, J.; Franck, N.; Guillaume, F.; Guillem, F.; Huron, C. \& Tiberghien, G. (2011). Comparison of RK and confidence judgment ROCs in recognition memory. Journal of Cognitive Psychology, 23/2, 171-184.

Mason, L.; Boldrin, A. \& Ariasi, N. (2010). Epistemic metacognition in context: evaluating and learning online information. Metacognition and Learning, 5, 67-90.

Mathabathe, K. C. \& Potgieter, M. (2014). Metacognitive monitoring and learning gain in foundation chemistry. Chemistry Education Research and Practice, 15, 94105 .

Metcalfe, J. \& Kornell, N. (2005). A region of proximal learning model of study time allocation. Journal of Memory and Language, 54, 463-477.

Metcalfe, J. (2009). Metacognitive judgments and control of study. Current Directions in Psychological Science, 18/3, 159-163.

Nelson, T. O. \& Narrens, L. (1990). Metamemory: A theoretical framework and new findings. Psychology of Learning and Motivation, 26, 125-173.

Norman, E.; Price, M. C. \& Duff, S. C. (2010). Trends and Prospects in Metacognition Research. New York, NY: Springer.

Norris, S. P. \& Phillips, L. M. (2012). Metacognitive in Science Education: Trends in Current Research. Dordrecht: Springer.

Overton, T.; Potter, N. \& Leng, C. (2013). A study of approaches to solving openended problems in chemistry. Chemistry Education Research and Practice, 14, 468475 .

Pulmones, R. (2010). Linking students' epistemological beliefs with their metacognition in a chemistry classroom. The Asia-Pacific Education Researcher, 19/1, 143-159.

Rummer, R.; Schweppe, J.; \& Schwede, A. (2016). Fortune is fickle: Null-effects of disfluency on learning outcomes. Metacognition Learning, 11/1, 57-70.

Sadowski, C., \& McIntosh, J. E. (2015). A phenomenological analysis of the experience of security and contentment for latency-aged children in shared-time parenting arrangements. Journal of Phenomenological Psychology, 46, 69-104.

Schraw, G.; Olafson, L.; Weibel, M., \& Sewing, D. (2012). Metacognitive in Science Education: Trends in Current Research. Dordrecht: Springer.

Schwartz, B. L.; Boduroglu, A., \& Tekean, A. I. (2016). Methodological concerns: The feeling-of-knowing task affects resolution. Metacognition Learning, 11/3, 305-316.

Siegel, M. A. (2012). Filling in the distance between us: Group metacognition during problem-solving in a secondary education course. Journal of Science Education and Technology, 21, 325-341. 
Sjostrom, J. \& Talanquer, V. (2014). Humanizing chemistry education: From simple contextualization multifaceted problematization, Journal of Chemical Education, 91/8, 1125-1131.

Sjostrom, J.; Eilks, I. \& Zuin, V. G. (2016). Towards eco-reflexive science education: A critical reflection about educational implications of green chemistry. Science Education, 25/3-4, 321-341.

Taber, K. S. (2014). Ethical considerations of chemistry education research involving 'human subjects'. Chemistry Education Research and Practice, 14, 109-113.

Thomas, R. C.; Finn, B. \& Jacoby, L. L. (2016). Prior experience shapes metacognitive judgments at the category level: The role of testing and category difficulty. Metacognition and Learning, 11/3, 257-274.

Tuysuzoglu, B. B., \& Greene, J. A. (2015). An investigation of the role of contingent metacognitive behavior in self-regulated learning. Metacognition Learning, 10/1, 77-98.

Veenman, M. V. J. (2012). Metacognitive in Science Education: Trends in Current Research. Dordrecht: Springer.

Vierkant, T. (2017). Phenomenology and The Cognitive Science. Dordrecht: Springer.

Yuksel, P., \& Yildirim, S. (2015). Theoretical frameworks, methods, and procedures for conducting phenomenological studies in educational settings. Turkish Online Journal of Qualitative Inquiry, 6/1, 1-20. 